\title{
Measurement of Young's modulus and residual stress of copper film electroplated on silicon wafer
}

\author{
Yong Zhou ${ }^{\mathrm{a} *}$, Chun-Sheng Yang ${ }^{\mathrm{a}}$, Ji-An Chen ${ }^{\mathrm{a}}$, Gui-Fu Ding ${ }^{\mathrm{a}}$, Wen Ding ${ }^{\mathrm{a}}$, Li Wang ${ }^{\mathrm{a}}$, \\ Ming-Jun Wang a, Ya-Ming Zhang ${ }^{\mathrm{a}}$, Tai-Hua Zhang ${ }^{\mathrm{b}}$ \\ ${ }^{a}$ Key Laboratory for Thin Film and Microfabrication of Ministry of Education, Research Institute of Micro/Nanometer Science and Technology, \\ Shanghai Jiao Tong University, Huashan Road 1954, Shanghai 200030, PR China \\ ${ }^{\mathrm{b}}$ State Key Laboratory of Non-linear Mechanics (LNM), Institute of Mechanics, Chinese Academy of Sciences, Beijing 100080, PR China
}

Received 7 April 2003; received in revised form 16 December 2003; accepted 20 January 2004

Available Online 27 March 2004

\begin{abstract}
The Young's modulus and residual stresses of electroplated copper film microbridges were measured. Special ceramic shaft structure was designed to solve the problem of getting the load-deflection curves of the microbridges from a nanoindentation system equipped with a normal Berkovich probe. Theoretical analysis of the load-deflection curves of the microbridges is proposed to evaluate the Young's modulus and residual stress of the copper films simultaneously. The calculated results based on the experimental measurements showed that the average Young's modulus and residual stress of the electroplated copper films are 115.2 $\mathrm{GPa}$ and 19.3 $\mathrm{MPa}$, respectively, while the Young's modulus measured by the nanoindenter for the same copper film with silicon substrate is $110 \pm 1.67 \mathrm{GPa}$.
\end{abstract}

(C) 2004 Elsevier B.V. All rights reserved.

Keywords: Copper film microbridges; Microelectromechanical systems; Mechanical properties; Load-deflection measurements

\section{Introduction}

Microelectromechanical systems (MEMS) is a new technology to manufacture microsystems, microdevices and microstructure whose dimensions are only a few hundred microns. The materials used in MEMS are always in thin film form, based on certain substrates or composite with other thin films, which have an important role on the performance of MEMS devices and microstructures. The deposition processes of thin film and different thermal expansion coefficient between thin film and substrate always lead to the residual stresses in thin films, which may change the performance of the devices. Characterizing, understanding and controlling the mechanical properties of MEMS materials have been an active research area during the recent years [1-5]. The mechanical behavior of thin films in thickness of a

\footnotetext{
*Corresponding author. Tel.: +86-2162933717; fax: +862162823631.

E-mail address: yzhou@mail.sjtu.edu.cn (Y. Zhou).
}

few microns might differ from those of the bulk material due to its size effect, micromachining method or specific microstructure. However, at present, it is difficult to establish a suitable technique and standard with high degree of accuracy for the measurements of mechanical properties of MEMS materials. Early work on the measurements of mechanical properties of thin films involved in the nanoindentation methods, wafer curvature testing, bulge testing, microtensile testing, resonant frequency testing and beam bending method.

The submicron nanoindentation of thin films on substrates is a common method to measure the hardness and Young's modulus, while thin film on different substrate and large pressure of the indenter may have influence on mechanical properties of thin films [6]. Wafer curvature method can be used to measure the average stress and strain of thin film, but the stresses are affected by the thermal expansion or growth mismatch between the substrate and thin film, and also the measured stress is an average value of large part of thin film with substrate [7]. The bulge testing uses a square 
or rectangular membrane to determine the residual stress and elastic modulus from the stress-strain curves, but the stress concentrations occurring at the four corners made it difficult to measure the yield strength and fracture strength of thin film [8], and the surface flaws presented in thin films may bring some errors. The sample holding problem is also occurred in microtensile testing [9], because the fragility of thin films and the flaws in sample are difficult to avoid in the microtensile testing. The resonant frequency method is used to measure the elastic modulus of a cantilever beam, but the experimental error may be large [10]. In order to avoid some of these difficulties, a new method based on the deflection of a free-standing cantilever microbeam has been developed [11], this method eliminates all the substrate effects, and can measure both the elastic and plastic properties, namely the Young's modulus and yield strength, also the experimental error is low by appropriatly selecting the size of the microbeam. However, this method may also bring some errors in determining the Young's modulus due to the spring of the nanoindenter, undercutting or insufficient etching at the beam support, slippage between the load applicator and the microbeam [12]. In order to obtain more the accurate data, Espinosa et al. [1] have proposed a three-dimensional computational modeling for testing thin films in RF (radio frequency) MEMS switches, that is, membrane deflection experiment (MDE) and numerical simulation were used to obtain the Young's modulus and residual stress of freestanding thin film membranes. In this method, nanoindenter was used to measure a membrane deflection, and finite element modeling was conducted using ABAQUS Implicit, version 5.7 in order to obtain the accurate values. Its main advantage is that measurement can be done accurately on wafer level. Later, Espinosa et al. [3-5] have modified this MDE to measure the mechanical properties of freestanding thin film, and the Young's modulus was obtained using a very simple equation. However, this method is somewhat complicated and expensive, and also critical for the measuring conditions. Recently, Zhang et al. [13] have set up a novel analysis method to evaluate Young's modulus as well as residual stress and bending strength simultaneously for thin film in the form of microbridges. This method uses the MEMS to fabricate samples and the sample holding problem and substrate effect can be avoided. In the same time, many samples having different sizes can be fabricated on the same wafer. Nanoindenter is used to measure the load- and unloaddeflection curves of thin film microbridges, and by combining the theoretical analysis model, the Young's modulus and residual stress can be obtained. It is really an effective way to evaluate two basic parameters for MEMS materials: Young's modulus and residual stress.

But their work was focused on non-metal films, such as silicon nitrides and oxides. For metal films, it is more

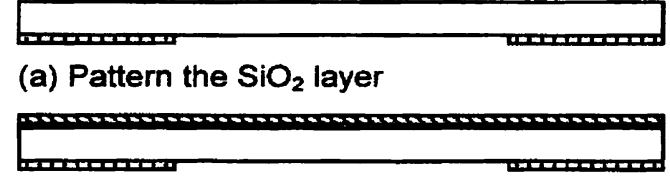

(b) Electroplate the Cu film

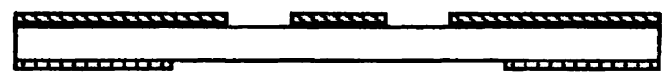

(c) Pattern the Cu film

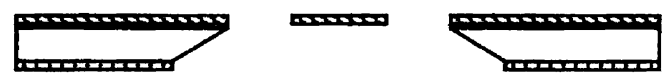

(d) Etch the silicon substrate

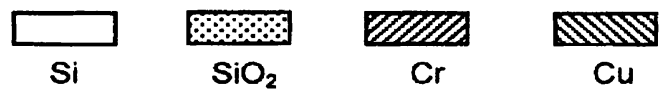

Fig. 1. Fabrication processes of $\mathrm{Cu}$ film microbridges.

difficult to get microbridge structure. One reason is that metal films are almost impossible to be patterned by dry etching, such as reactive ion etching (RIE), or by chemical wet etching. During the wet etching processes, it's difficult to control the micro size exactly. The other reason is that the metal film can hardly withstand the chemical etching solution for a long time during the bulk silicon etching. Boutry et al. [14] has ever tried to fabricate metal thin film microbridges by RIE to get rid of the silicon substrate, but the particle bombardment during the RIE has some alternation of thin film characteristic. In the present work, we used MEMS to overcome these difficulties, and succeeded in fabricating the copper film microbridges. The residual stress and Young's modulus of copper film microbridges are evaluated based on the measured load- and unload-deflection curves.

\section{Experimental details}

Copper film is one of the most important MEMS materials used in microsystems, mechatronic components and microprocessors. Many copper films are prepared by sputtering or electroplated with photoresist mask [15-18]. In this paper, the microbridge samples were electroplated $\mathrm{Cu}$ films based on single crystal silicon substrate with a width of several hundred microns. The major microfabrication steps for the microbridges are shown in Fig. 1. (a) Three inches, ptype (100) silicon wafer was thermally oxidized. The thickness of $\mathrm{SiO}_{2}$ layer was approximately $2.5 \mu \mathrm{m}$. One side of the $\mathrm{SiO}_{2}$ layers was etched off in the buffered $\mathrm{HF}$ solution, while the other side of the $\mathrm{SiO}_{2}$ layer was patterned to determine the rectangular $\mathrm{Si}$ etching window; (b) on the exposed silicon side, the Cr layer with a thickness of $10 \mathrm{~nm}$ was sputter-deposited as adhesion layer, and then a $\mathrm{Cu}$ layer with thickness of approximately $80 \mathrm{~nm}$ was sputter-deposited as a seed layer for 


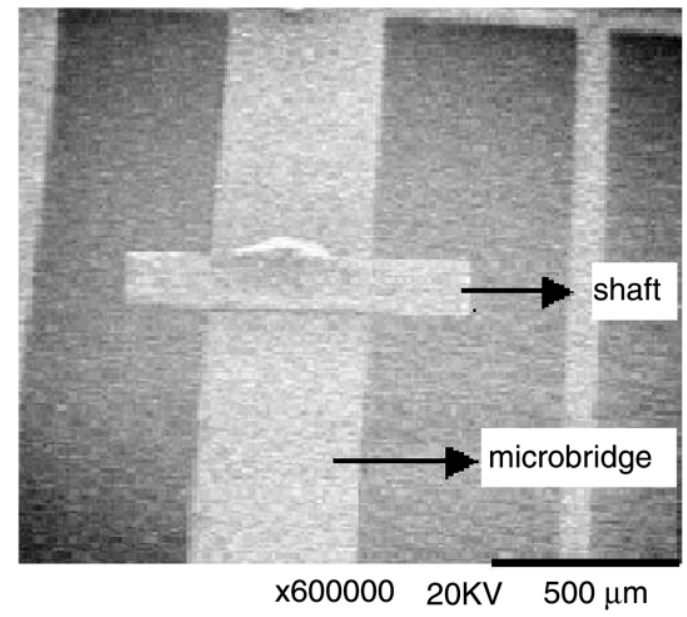

Fig. 2. Structures of $\mathrm{Cu}$ film microbridges.

electroplating; (c) bulk $\mathrm{Cu}$ film was electroplated to the desired thickness, and then patterned by the diluted $\mathrm{FeCl}_{3}$ solution, then the thin $\mathrm{Cr}$ layer was etched off by the $\mathrm{Ce}\left(\mathrm{SO}_{4}\right)_{2} \cdot 2\left(\mathrm{NH}_{4}\right)_{2} \mathrm{SO}_{4}$ solution as to expose silicon substrate; and (d) silicon substrate was bulk micromachined by the $\mathrm{KOH}$ anisotropic solution with the etch mask of $\mathrm{SiO}_{2}$. The etching conditions are: $T=80{ }^{\circ} \mathrm{C}$, $\mathrm{H}_{2} \mathrm{O}: \mathrm{KOH}=100: 40$ (weight ratio). To prevent the $\mathrm{Cu}$ film from a long time immerging in the hot $\mathrm{KOH}$ solution, the silicon substrate was put into a boot clamp, leaving only the side of $\mathrm{Si}$ to contact the $\mathrm{KOH}$ solution. After the silicon substrate was etched through, the $\mathrm{Cr}$ layer under the $\mathrm{Cu}$ film bridges was removed again by the $\mathrm{Ce}\left(\mathrm{SO}_{4}\right)_{2} \cdot 2\left(\mathrm{NH}_{4}\right)_{2} \mathrm{SO}_{4}$ solution. Thus, a freestanding copper film microbridge was fabricated. For the deposition of $\mathrm{Cu}$ thin film, the direct current (DC) for electrodeposition was used and the electrolyte was composed of $\mathrm{CuSO}_{4} \cdot 5 \mathrm{H}_{2} \mathrm{O}(100 \mathrm{~g} / \mathrm{l}), \mathrm{H}_{2} \mathrm{SO}_{4}(200 \mathrm{ml} / \mathrm{l})$ and $\mathrm{CI}^{-}(80 \mathrm{ppm})$. The electrodepositing rate is approximately $0.3 \mu \mathrm{m} / \mathrm{min}$. The length of the microbridge ranges from 1000 to $2000 \mu \mathrm{m}$, and its width is in the range of 200-1000 $\mu \mathrm{m}$. The thickness of the microbridges for all samples was $9.4 \mu \mathrm{m}$. The distances between each microbridges were larger than $500 \mu \mathrm{m}$. Fig. 2 shows the fabricated $\mathrm{Cu}$ film microbridges.

The $\mathrm{Cu}$ film microbridge testing was conducted on a nanoindenter XP system with normal Berkovich probe. To distribute the indentation force uniformly on the center of the bridge, a stiff shaft was fabricated by precision machining and glued at the center of the bridges because a long wedge tip is not available, as shown in Fig. 2. The material for the shaft is a kind of stiff ceramics, and its size is $600 \times 80 \times 50 \mu \mathrm{m}$. When the diamond Berkovich probe presses on the ceramic shaft, the similar load behavior is realized as that of a wedge tip.

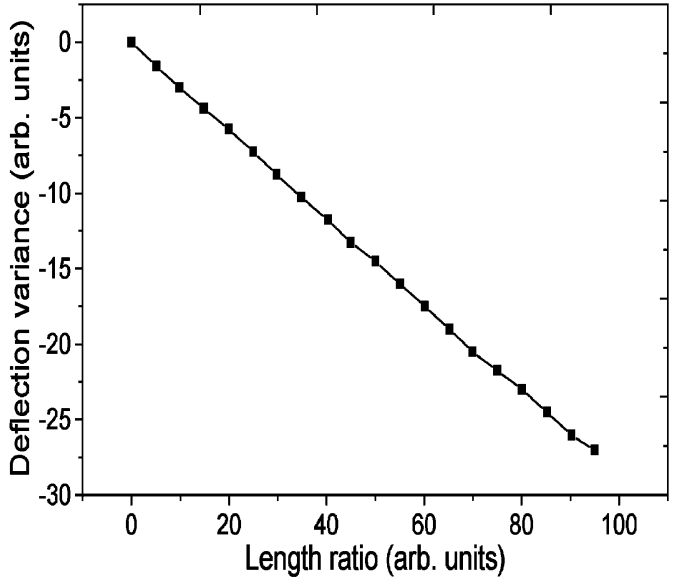

Fig. 3. The dependence of microbridge deflection on length ratio of the shaft and the microbridge.

\section{Analytical model}

\subsection{Effects of the shaft on the center deflection}

Since the shaft fixed on the bridge center has certain size, the load distribution at the bridge center must not be the same as that with a wedge tip. To evaluate this influence, we conducted FEM (finite element method) analysis to get the variance. The analysis is performed in the software package ANSYS 6.0 University High. Fig. 3 shows the dependence of the microbridge deflection on the length ratio of the shaft and the microbridge. One can see that when the length ratio is within $10 \%$, the deflection variance is within 3\%. For our testing samples, the width of the shaft is $80 \mu \mathrm{m}$, while the length of the microbridge is more than $1000 \mu \mathrm{m}$, so the

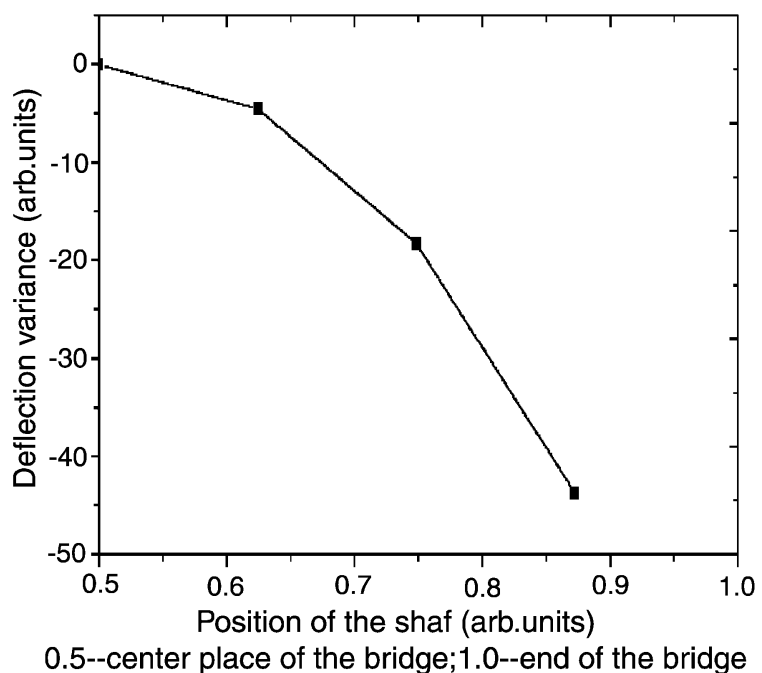

Fig. 4. The dependence of microbridge deflection on the positions of the shaft. 
influence of the shaft on the deflection of the microbridges should be within $3 \%$.

However, the shaft is fixed by the precision machining method; there must be some excursion of its position from the center. Fig. 4 shows the deflection variance as the function of the shaft position. It can be noticed that when the deviation of the shaft from the center position of the bridge is within $12.5 \%$, the deflection variance is just within 5\%, which is also acceptable for our measurements.

\subsection{Evaluation of the Young's modulus and residual stress}

After the load- and unload-deflection curves are got by the nanoindenter measurements, the Young's modulus and residual stress can be determined by fitting the experimental load- and unload-deflection curves with the theoretical solution by the least square technique, as described in Ref. [13]:

$S=\sum_{i=1}^{n}\left[w_{i}^{e}\left(Q_{i}\right)-w_{i}^{t}\left(Q_{i}, N_{\mathrm{r}}, E_{\mathrm{f}}\right)\right]^{2}$

where $n$ is the number of data, $w_{i}^{e}$ is the experimentally observed deflection, and $w_{i}^{t}\left(Q_{i}, N_{\mathrm{r}}, E_{\mathrm{f}}\right)$ is the theoretical deflection obtained by the following equations:

$w=-\frac{Q \tanh (k l / 2)}{2 N_{\mathrm{r}} k}+\frac{Q l}{4 N_{\mathrm{r}}}-\frac{M_{0}}{N_{\mathrm{r}}}\left[\frac{1}{\cosh (k l / 2)}-1\right]$

and

$M_{0}=\frac{Q\left[\frac{1}{\cosh (k l / 2)}-1\right]}{2 k \tanh (k l / 2)}$

with $k=\sqrt{N_{\mathrm{r}} / D}, D=E_{\mathrm{f}} t^{3} / 12$, where $Q$ is the load force per unit width of the microbridge, $l$ and $t$ is the length

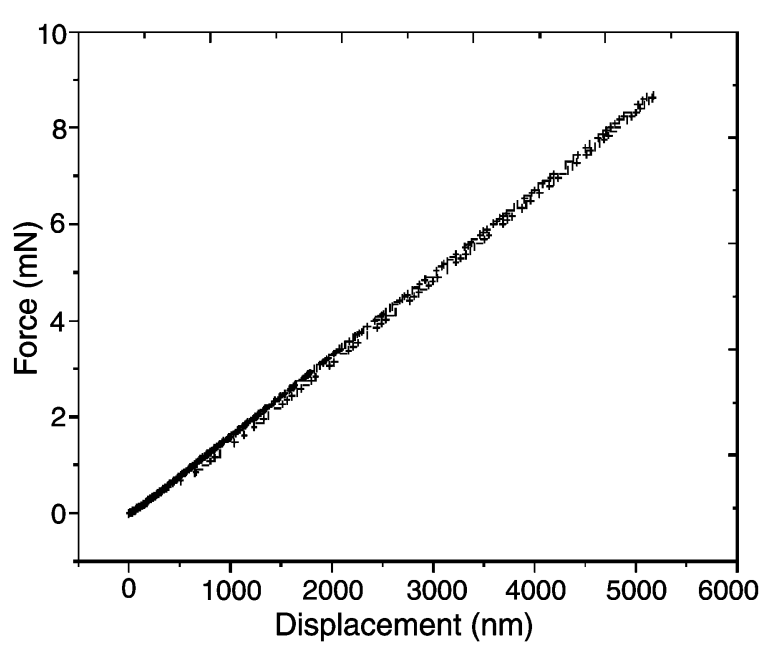

Fig. 5. Measured typical load-deflection curves of the $\mathrm{Cu}$ film microbridges for sample 1 .

and thickness of the microbridge, respectively. The iteration technique is used to regress the Young's modulus $E_{\mathrm{f}}$ and residual force $N_{\mathrm{r}}$, which gives the residual stress as $\sigma_{\mathrm{r}}=N_{\mathrm{r}} / t$.

\section{Results and discussion}

Table 1 lists the sizes of copper film microbridge and the evaluated Young's modulus and residual stress. The Young's modulus and residual stress is calculated by the iteration method as described in Section 3.2. The typical experimental load- and unload-deflection curves of these samples are shown in Fig. 5.

From the calculated results, one can find that the average value of Young's modulus of $\mathrm{Cu}$ film microbridges is approximately $115 \mathrm{GPa}$, which is lower than the value of $130 \mathrm{GPa}$ of the bulk polycrystalline copper [19], but in good agreement with that of bulk $\mathrm{Cu}$ film reported by Jamting et al. [15]. Farhat et al. [16] has reported a Young's modulus of $102.46 \pm 2.5 \mathrm{GPa}$ of assputtered $\mathrm{Cu}$ film by the nanoindentation method, which is also lower than that of bulk polycrystalline $\mathrm{Cu}$ [19], but in accordance with the result of Huang et al. [17]

Table 1

Size, Young's modulus and residual stress of copper film microbridges

\begin{tabular}{llllll}
\hline Sample & $\begin{array}{l}\text { Length } \\
(\mu \mathrm{m})\end{array}$ & $\begin{array}{l}\text { Width } \\
(\mu \mathrm{m})\end{array}$ & $\begin{array}{l}\text { Thickness } \\
(\mu \mathrm{m})\end{array}$ & $\begin{array}{l}\text { Young's modulus } \\
(\mathrm{GPa})\end{array}$ & $\begin{array}{l}\text { Residual stress } \\
(\mathrm{MPa})\end{array}$ \\
\hline 1 & 1530 & 960 & 9.4 & 119.5 & 32.74 \\
2 & 1513 & 466 & 9.4 & 116.2 & 28.8 \\
3 & 1525 & 468 & 9.4 & 1.3 & 108.3 \\
4 & 1519 & 464 & 9.4 & 110 & 7.1 \\
5 & 1010 & 363 & 9.4 & 118.2 & 13.2 \\
6 & 1017 & 453 & 9.4 & 113 & 26.6 \\
7 & 1017 & 260 & 9.4 & 115.2 & 11.0 \\
8 & 2015 & 957 & 9.4 & & 19.3 \\
Average values & & & & \\
\hline
\end{tabular}




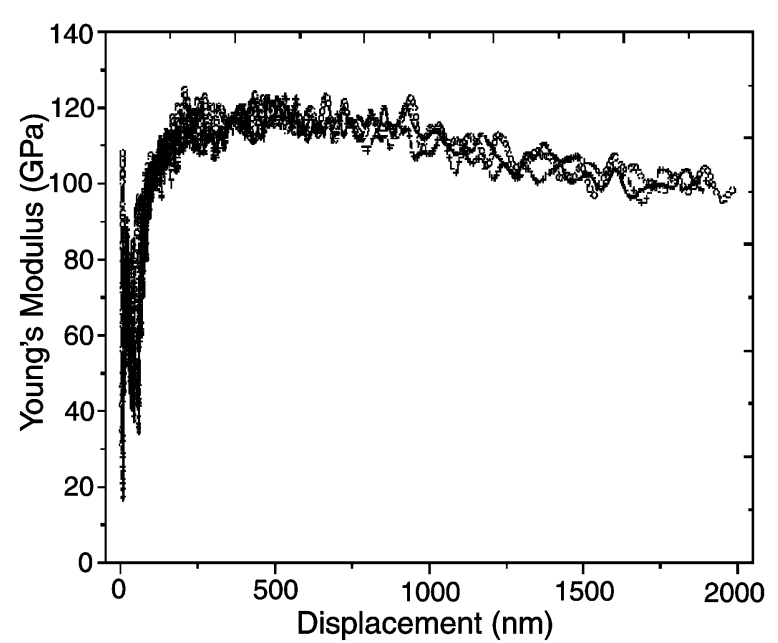

Fig. 6. Nanoindentation measurement of electroplated copper film with silicon substrate for sample 1 .

by tensile testing of freestanding $\mathrm{Cu}$ film deposited by electron-beam evaporation. Read [20] has measured the electron-beam deposited and sputtered $\mathrm{Cu}$ film by the nanoindenter, and the Young's modulus was $99 \mathrm{GPa}$ and $109 \mathrm{GPa}$, respectively. Recently, Fang et al. [18] have investigated the mechanical properties of $\mathrm{Cu}$ films on $\mathrm{Si}, \mathrm{SiO}_{2}$ and $\mathrm{LiNbO}_{3}$ substrates by the nanoindenter and found the Young's modulus is $135 \mathrm{GPa}$ and $100 \mathrm{GPa}$ on $\mathrm{LiNbO}_{3}$ and $\mathrm{Si}$ sbustrate, respectively, which is in accordance with the results of Gouldstone et al. [21] and Sanders et al. [22]. Our results are comparable to the results in Refs. [15-17], but lower than that of results as reported in Refs. [18,21,22]. It has been shown by Kalantary [23] that the hardness of the electroplated copper film is dependent on electrolyte constituents and the pulsing conditions. They also have found that the tensile strength is affected by direct current and pulsed current for the electrodeposition and the pulsing conditions. Thus, it is believed that the differences in Young's modulus of copper films are due to the different preparation methods or preparation conditions. Normally, the nanoindenter XP system can measure the Young's modulus of thin films with substrates, which is called the nanoindentation method. Here, we also measured the Young's modulus of the $\mathrm{Cu}$ film with silicon substrate by the nanoindenter, and the mean value of the Young's modulus is $110.61 \pm 1.67 \mathrm{GPa}$, as shown in Fig. 6 .

The calculated results prove that the mathematical equations and the iteration processes to regress the mechanical parameters are somehow accurate to get the Young's modulus values, and the attached shaft structure on the microbridge does little effect on the results.

During the iteration processes, we can also get the residual stresses with Young's modulus for the microbridges. For our electroplated copper samples, the average value is $19.3 \mathrm{MPa}$, which is very low than the sputtered
$\mathrm{Cu}$ film. The difference in residual stress for the microbridges may be due to the size effect. The small residual stress in the $\mathrm{Cu}$ film microbridges corresponds to the phenomenon that the copper film does not show any sign of peeling up at the edge of the 3-inch silicon wafer.

In addition, it is clear from Table 1 that there is a variation in Young's modulus and residual stress for the copper film microbridges. One possible reason is due to the current distribution in the fabrication process of the $\mathrm{Cu}$ film, this may result in non-uniformity in film thickness. It is shown that in the analytical model the change in film thickness of $10 \mathrm{~nm}$ will result in an evident change in Young's modulus and residual stress, so it is critical for the measurement of film thickness. Furthermore, some flaws in the copper film microbridges may have effects on the measurements. The other possible reason is that the position where the nanoindenter tip pressed on the microbridge may deviate from the central position of the film microbridge this may lead to some errors in measuring the load- and unloaddeflection curves. However, when the nanoindenter is used to measure the load- and unload-deflection curves, at the beginning, the measured data in the loaddeflection curve is not useful because the contact state between the tip and the copper film microbridge is not very stable, this may bring errors in evaluating the Young's modulus and residual stress. Thus, the evaluated data based on the load deflection curves has some scatters.

\section{Acknowledgments}

This work is fully supported by the Key Fundamental Research and Development Program (G1999033103) from Ministry of Science and Technology of China. The measurements were conducted at the State Key Laboratory of Non-linear Mechanics (LNM) of Institute of Mechanics, Chinese Academy of Sciences.

\section{References}

[1] H.D. Espinosa, M. Fischer, Y. Zhu, S. Lee, in: M. Laudon, B. Romanowicz (Eds.). Proceedings of the 4th International Conference on Modeling and Simulation of Microsystems, Hilton Head Island, South Carolina, USA, March 19-21, 2001, Applied Computational Research Society, p. 402.

[2] T. Yi, C.J. Kim, Meas. Sci. Technol. 10 (1999) 706.

[3] H.D. Espinosa, B.C. Prorok, Y. Zhu, Proceedings of IPACK'01, The Pacific Rim/ASME International Electronic Packaging Technical Conference and Exhibition, Kauai, Hawaii, USA, July 8-13, 2001, p. 1.

[4] H.D. Espinosa, B.C. Prorok, Proceedings of the SEM annual Conference on Experimental and Applied Mechanics, Portland, Oregon, USA, June 4-6, 2001, p. 446.

[5] H.D. Espinosa, B.C. Prorok, M. Fischer, J. Mech. Phys. Solids 51 (2003) 47.

[6] M.F. Doerner, W.D. Nix, J. Mater. Res. 1 (1986) 601. 
[7] E.J. McInerney, P.A. Flinn, Proceedings of the 20th Annual International Reliability Symposium, San Diego, CA, USA, IEEE Electron Devices and Reliability Societies, 1982, p. 264.

[8] J.J. Vlassak, W.D. Nix, J. Mater. Res. 7 (1992) 3242.

[9] K. Yoshii, T. Tagaki, M. Umeno, H. Kawabe, J. Phys. E Sci. Instrum. 16 (1983) 127.

[10] K.E. Peterson, C.R. Guarnieri, J. Appl. Phys. 50 (1979) 6761.

[11] T.P. Weihs, S. Hong, J.C. Bravman, W.D. Nix, J. Mater. Res. 3 (1988) 931.

[12] J.-A. Schweitz, MRS Bull. 17 (1992) 34.

[13] T.Y. Zhang, Y.J. Su, C.F. Qian, M.H. Zhao, L.Q. Chen, Acta Mater. 48 (2000) 2843.

[14] M. Boutry, A. Bosseboeuf, G. Coffignal, SPIE 2879 (1996) 126.
[15] A.K. Jamting, J.M. Bell, M.V. Swain, N. Schwarzer, Thin Solid Films 308-309 (1997) 304.

[16] Z.N. Farhat, Y. Ding, D.O. Northwood, Surf. Coat. Technol. 89 (1997) 24.

[17] H.B. Huang, F. Spaepen, Acta Mater. 48 (2000) 3261.

[18] T.H. Fang, W.J. Chang, Microelectron. Eng. 65 (2002) 231.

[19] C.J. Smithells, Smithells Metals Reference Book, Butterworths, London, 1983, p. 152.

[20] D.T. Read, Meas. Sci. Technol. 9 (1998) 676.

[21] A. Gouldstone, H.J. Koa, K.Y. Zeng, Acta Mater. 48 (2000) 2277.

[22] P.G. Sanders, J.A. Eastman, Acta Mater. 45 (1997) 4019.

[23] M.R. Kalantary, D.R. Gabe, J. Mater. Sci. 30 (1995) 4515. 